\title{
Review
}

\section{Role of LCAT in Atherosclerosis}

\author{
Alice Ossoli ${ }^{1}$, Sara Simonelli ${ }^{1}$, Cecilia Vitali ${ }^{1}$, Guido Franceschini ${ }^{1,2}$ and Laura Calabresi ${ }^{1}$ \\ ${ }^{1}$ Centro Grossi Paoletti, Dipartimento di Scienze Farmacologiche e Biomolecolari, Università degli Studi di Milano, Milano, Italy \\ ${ }^{2}$ Division of Chemical and Biomolecular Sciences - DeFENS, Università degli Studi di Milano, Milano, Italy
}

Lecithin:cholesterol acyltransferase (LCAT) is the only enzyme capable of esterifying cholesterol in plasma, thus determining the maturation of high-density lipoproteins. Because it maintains an unesterified cholesterol gradient between peripheral cells and extracellular acceptors, for a long time, LCAT has been considered as a key enzyme in reverse cholesterol transport. However, despite the fact that it has been more than 50 years since the identification of LCAT, the role of this enzyme in the pathogenesis of atherosclerosis is still debated. A number of studies have been conducted in different animal models, with contradictory results. Studies in humans, in particular in the general population, in subjects at high cardiovascular risk, and in carriers of genetic LCAT deficiency in an excellent model to evaluate the correlation between the reduction of LCAT activity and atherosclerosis also gave conflicting results. This review provides a comprehensive overview of the controversial findings obtained in animals and humans, strengthening the necessity of further investigation to establish how LCAT could be regulated in a promising therapeutic strategy to reduce cardiovascular risk.

J Atheroscler Thromb, 2016; 23: 119-127.

Key words: Lecithin:cholesterol acyltransferase, HDL, Atherosclerosis, Genetic LCAT deficiency

\section{Introduction}

Lecithin:cholesterol acyltransferase (LCAT), first identified by Glomset ${ }^{1)}$, is a lipoprotein-associated enzyme responsible for the synthesis of most of the plasma cholesteryl esters (CE), and as a consequence, for the maturation of high density-lipoproteins $(\mathrm{HDL})^{2)}$. Besides its primary function in HDL metabolism, LCAT has long been believed to exert an important role in reverse cholesterol transport (RCT), the process to explain the HDL-mediated atheroprotection. The complex role of this enzyme in modulating lipoprotein metabolism, in RCT, and especially in atherosclerosis has been extensively studied, but it is still under discussion, becoming a topic of great interest in the cardiovascular field.

Address for correspondence: Laura Calabresi, Department of Pharmacological and Biomolecular Sciences, University of Milano, Via Balzaretti 9, 20133 Milano, Italy

E-mail: Laura.Calabresi@unimi.it

Received: September 7, 2015

Accepted for publication: October 13, 2015

\section{The LCAT Enzyme}

The LCAT gene $(-4.5 \mathrm{~kb})$ is located on chromosome 16 (region 16q22), it contains six exons, with a coding sequence of $\sim 1.5 \mathrm{~kb}^{3)}$; liver is the primary site of LCAT synthesis, but other tissues, such as the brain and testes, produce a small amount of $\mathrm{LCAT}^{4)}$. The fully mature protein, containing 416 amino acids and with an approximate molecular weight of $67 \mathrm{kDa}$, circulates in plasma reversibly bound mainly to $\mathrm{HDL}$ particles, but also to apolipoprotein B (apoB)-containing lipoproteins. Very recently, the 3D structure of LCAT has been solved by two different research groups $^{5,6)}$; as predicted, LCAT has an $\alpha / \beta$ hydrolase fold with Ser181, Asp345, and His377 required for catalytic activity (Fig.1). However, other questions, such as how the enzyme interacts with its substrate, or with HDL and apoA-I, and whether LCAT changes its conformation upon this interactions, remain unsolved $^{6}$.

The plasma LCAT concentration is approximately $5 \mu \mathrm{g} / \mathrm{mL}$, and it slightly modifies in adult humans by gender, age, and smoking and alimentary habits $^{7}$; the mass of the enzyme in plasma compartment can be measured by immunoenzymatic assays ${ }^{8)}$. 


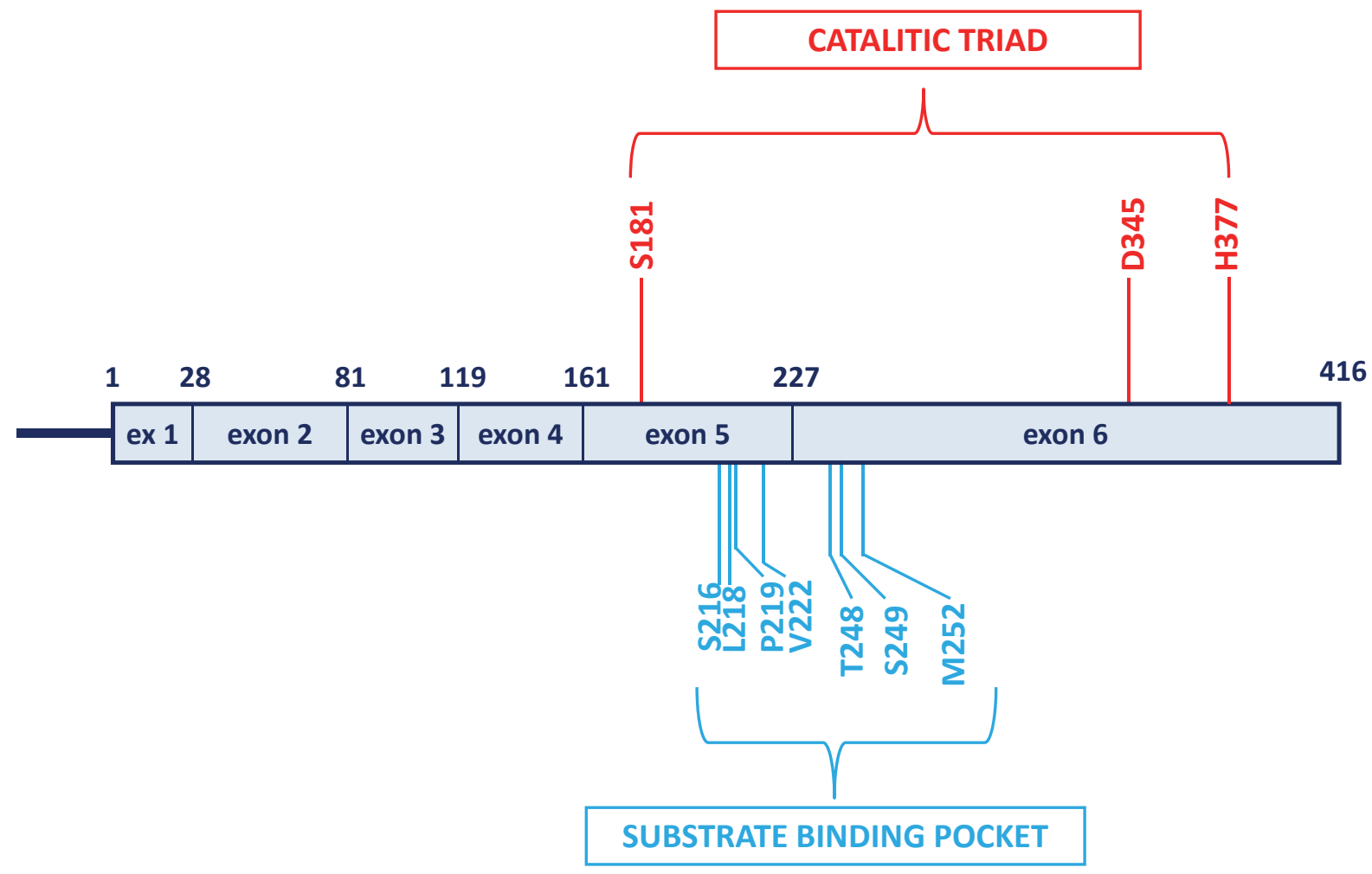

Fig. 1. LCAT gene structure. LCAT coding region contains six exons and the main domain functions consist in a catalytic triad (Ser181, Asp345, and His377) and in a subdomain (Ser216, Lys218, Pro219, Val222, Thr248, Ser249, and Met252) that helps shape the back wall of the substrate binding pocket (6).

LCAT function can be measured using different assays, but there is no standard procedure, which can possibly contribute to explain the differences observed among different studies. The unesterified/total cholesterol ratio (UC/TC), which can be easily determined by standard enzymatic techniques, is a marker of the efficiency of the cholesterol esterification process in plasma. The enzyme ability to esterify cholesterol can be determined by measuring the following: (i) the LCAT activity, which is a measure of the enzyme ability to esterify cholesterol in a standardized exogenous substrate, normally a reconstituted HDL and (ii) the cholesterol esterification rate (CER), which is a measure of the enzyme ability to esterify cholesterol in endogenous lipoproteins ${ }^{9}$. In our experience, CER is not the preferable assay to evaluate LCAT functionality; indeed, it depends not only on enzyme activity itself but also on lipoprotein integrity, on adequate sample handling, on storage time of plasma until assayed, and finally, on the type of endogenous lipoprotein particles. It has been shown that samples enriched in pre $\beta$-HDL, a good substrate for LCAT, show increased cholesterol esterification when measured as $\mathrm{CER}^{10)}$. LCAT activity is less susceptible to sample preparation or storage time, and in the absence of gene mutations, it correlates with plasma LCAT concentration. These three assays (LCAT mass, LCAT activity, and CER) should be used together as they provide complementary information on the concentration of the enzyme, its activity, and the functionality of the entire cholesterol esterification process.

LCAT is the only enzyme capable of esterifying cholesterol in plasma through a transesterification reaction, in which the conversion of cholesterol and phosphatidylcholine (or lecithin) to cholesteryl ester and lysophosphatidylcholine occurs. This reaction occurs in the following two steps: LCAT first cleaves the fatty acid from the sn-2 position of lecithin, by its phospholipase A2 activity, and transfers it onto Ser181, and then, through its acyltransferase activity, LCAT can transesterify the cleaved fatty acid onto the hydroxyl group of cholesterol ${ }^{3)}$. Apolipoprotein A-I (apoA-I), the main protein component of HDL, is the best LCAT activator in plasma; apoE can activate LCAT in plasma in apoB-containing lipoproteins ${ }^{11)}$ and is the major LCAT activator in other fluids such as the cerebrospinal fluid ${ }^{12}$. LCAT can be activated by other apolipoproteins, such as apoA-II, apo A-IV, 
apoC-I, and apoC-III, but much less efficiently ${ }^{13)}$.

\section{LCAT and HDL Metabolism}

LCAT is a key enzyme in lipoprotein metabolism because it allows the maturation of HDL particles. The preferred lipoprotein substrate for LCAT is a newly assembled small, discoidal pre $\beta$-HDL, generated through the interaction of lipid-free or lipid-poor apoA-I with a ATP-binding cassette A1 (ABCA1) transporter with subsequent efflux of phospholipids and unesterified cholesterol ${ }^{2)}$. On interaction with LCAT, pre $\beta$-HDL is converted to mature, spherical, and $\alpha$-migrating HDL, which comprise most of the plasma HDL. Pre $\beta$-HDL has a short plasma half-life because the kidney removes this particles quickly ${ }^{14)}$, whereas $\alpha$-HDL has a slower turnover ${ }^{15)}$. Thus, LCAT plays a central role in intravascular HDL metabolism and in determining plasma HDL level.

For a long time, LCAT has also been considered as one of the most important driving force behind RCT, the process by which excess cholesterol is removed from peripheral cells, including arterial wall macrophages, and carried to the liver for biliary excretion ${ }^{16)}$. By cholesterol esterification in HDL, LCAT contributes to maintain the unesterified cholesterol gradient between the cell membrane and extracellular acceptors, establishing a continuous flux of cholesterol from periphery to circulating lipoproteins and preventing cholesterol reuptake by the cells ${ }^{1,17)}$. However, recent data have questioned the role of LCAT in RCT. Human LCAT overexpression in mice remarkably increases plasma HDL levels but does not enhance $\mathrm{RCT}^{18)}$, and conversely, a substantial in vivo macrophage RCT occurs in LCAT-deficient mice despite the severe plasma HDL reduction ${ }^{18)}$. Consistent with these animal studies, early data in humans showed that HDL can deliver large amounts of unesterified cholesterol directly to the liver ${ }^{19,20)}$.

\section{HDL Metabolism in LCAT Deficiency}

Genetic LCAT deficiency is a rare inherited disorder due to loss-of-function mutations in LCAT gene leading to the following two different syndromes: classic familial LCAT deficiency (FLD) and fish-eye disease (FED), both characterized by very low HDL lev$\mathrm{els}^{21)}$. In FLD cases, the lack of LCAT activity is complete, and the enzyme loses its ability to esterify cholesterol in both HDL and LDL particles with severe clinical manifestations such as corneal opacity, anemia, and renal disease ${ }^{22)}$. In FED cases, the enzyme loses its ability to esterify cholesterol in HDL, whereas in LDL the activity is retained, thus leading to less severe clinical manifestations, which are normally limited to corneal opacity and occasionally to anemia and renal disease $^{22)}$.

Lipid and lipoprotein metabolism is significantly altered in both FLD and FED carriers of two mutant $L C A T$ alleles. Lipid profile is characterized by an increased percentage of unesterified cholesterol and hypertryglyceridemia and a dramatic reduction in HDL-C $(<10 \mathrm{mg} / \mathrm{dL}$ in FLD and $<27 \mathrm{mg} / \mathrm{dL}$ in FED) and apoA-I $(<30 \mathrm{mg} / \mathrm{dl})$ levels ${ }^{9}$. Plasma LDL-C levels show a wide interindividual variability but are often in normal/low range, and only in FLD subjects, LDL are smaller and are enriched in triglycerides, whereas in FED carriers the LDL composition is quite unaltered because of the residual LCAT activity $^{22}$. The most remarkable changes in lipoprotein profile are the drastic alteration in HDL structure and subclass distribution and the presence of an abnormal lipoprotein called lipoprotein X (LpX), usually absent in physiological condition and detectable in plasma only in some pathological conditions ${ }^{22)}$. HDL from carriers of two mutant LCAT alleles are selectively depleted in large particles with predominance of small $\mathrm{HDL}^{23)}$. These changes reflect the accumulation in plasma of CE-poor discoidal HDL ${ }^{24)}$, that are not able to mature into spherical HDL ${ }^{14)}$. Heterozygous carriers show an intermediate biochemical phenotype, characterized by reduced plasma HLD-C and apoA-I levels, and an enrichment in small-apoA-I containing particles ${ }^{23)}$.

\section{LCAT and Atherosclerosis in Animal Models}

Because of LCAT role in the HDL maturation process and in atheroprotective reverse cholesterol transport pathway, variations in LCAT activity seem to be naturally implicated in atherosclerosis prevention or development. From 1970 to date, a large number of studies have been performed in both animal models and humans exploring LCAT role in atherosclerosis (Table 1).

A number of animal studies, in at least four different species, have been conducted to explore the role of LCAT in atherosclerosis. The first studies were performed in 1995 in mice that overexpress LCAT gene. Two different independent groups created LCAT transgenic mice on a $\mathrm{C} 57 \mathrm{Bl} / 6$ background, containing 15-120 copies of the transgene ${ }^{25,26)}$. LCAT overexpression led to a marked increase in HDL-C levels and modification in HDL composition; particles were larger in size and enriched in CE and phospholipids ${ }^{25}$. After atherogenic diet, mice developed from 
Table 1. LCAT and atherosclerosis in animal models

\begin{tabular}{lcccc}
\hline & $\begin{array}{c}\text { LCAT } \\
\text { overexpression }\end{array}$ & $\begin{array}{c}\text { LCAT } \\
\text { downregulation }\end{array}$ & Atherosclerosis & Source \\
\hline Mouse & $\checkmark$ & $\uparrow$ & Vaisman BL, 1995; Mehlum A, 1997; Berard AM, 1997 \\
SR-BI deficient mouse & $\checkmark$ & $\downarrow$ & Thacker S, 2015 \\
Mouse & & $\downarrow$ & $\downarrow$ & Furbee JW, Jr, 2002; Lambert G, 2001 \\
Rabbit & $\checkmark$ & & Hoeg JM, 1996; Hoeg JM, 1996 \\
Squirrel monkey & $\checkmark$ & $?$ & Amar MJ, 2009 \\
\hline
\end{tabular}

1.8-fold to 3.5-fold larger atherosclerotic lesions correlated with the number of copies of the human transgene integrated compared with controls with physiological levels of LCAT $^{26,27)}$. The results obtained from these studies suggest that LCAT overexpression does not protect against atherosclerosis. This is probably because of the accumulation of dysfunctional large apoE-rich HDL in the plasma of transgenic mice, which were shown to be defective in the delivery of cholesterol to the liver through scavenger receptor class B, type I (SR-BI) ${ }^{27)}$. On the contrary, in SR-BI deficient mice the LCAT overexpression led to an antiatherogenic lipoprotein profile with lower VLDL and LDL levels and majority of cholesterol in HDL, resulting in a decreased diet-induced atherosclerosis ${ }^{28)}$. Some years later, Foger et al generated LCAT transgenic mice also expressing cholesteryl ester transfer protein (CETP), which in humans represents an alternative pathway for the delivery of HDL cholesterol to the liver; atherosclerotic lesions were reduced compared with LCAT transgenic mice, but still 1.9-fold larger compared with lesions detected in control and single CETP transgenic animals ${ }^{29)}$.

On the other hand, lack of LCAT gene seems to be atheroprotective in mice. A mouse model of human LCAT deficiency was generated by targeted disruption of the LCAT gene in mouse embryonic stem cells ${ }^{30,31)}$, with the generation of LCAT knock-out (LCAT KO) mice with no detectable LCAT activity and significant reduction in HDL cholesterol levels. As observed in humans, $\alpha$-HDL levels and size were significantly reduced in LCAT $\mathrm{KO}$ mice, whereas pre $\beta$-HDL particles were increased ${ }^{30)}$. When LCAT KO mice were kept on atherogenic diet or crossed with LDL receptor $\mathrm{KO}$ mice or apoE KO mice, LCAT deficiency appeared to be atheroprotective ${ }^{32,33)}$.

Rabbit expresses CETP and develops diet-induced atherosclerosis, and thus, it has been widely used in lipoprotein and atherosclerosis research. In 1996, transgenic rabbits containing 38-1,436 copies of the human LCAT transgene were generated ${ }^{34)}$. Overexpression of human LCAT in rabbits led to marked increase of large HDL particles containing apoE and reduction of apoB-containing particles ${ }^{34)}$. After atherogenic diet, LCAT transgenic rabbits showed 7-fold reduction in aortic lesions compared with control rabbits $^{35)}$.

In a more recent study, LCAT was overexpressed in squirrel monkeys through adenoviral vector ${ }^{36}$. Squirrel monkeys express both CETP, like humans and rabbits, and apoA-II that is not expressed in rabbit. The overexpression of LCAT led to an antiatherogenic lipoprotein profile with increased HDL-C levels and reduction in apoB-containing particles ${ }^{36}$, but no further studies were conducted on atherosclerosis in this model.

The contradictory results obtained with the various species do not clarify the role of LCAT in atherosclerosis, and unsolved questions are still under investigation.

\section{LCAT and Atherosclerosis in Humans}

As observed in animal studies, the role of LCAT in the pathogenesis of human atherosclerosis is also controversial. The possible contribution of LCAT in determining human atherosclerosis was investigated in the general population, in subjects at high risk for the development of cardiovascular diseases, and in carriers of genetic LCAT deficiency (Table 2).

\section{General Population}

The EPIC-Norfolk was the first prospective study investigating the correlation between plasma LCAT levels and atherosclerosis in the general population, involving more than 2,700 subjects ${ }^{37)}$. Among all enrolled subjects, 993 individuals developed coronary artery disease (CAD). Subjects were divided into quartiles according to the plasma LCAT concentration, and among quartiles, no association was observed between plasma LCAT levels and risk to develop future CAD. When individuals were divided by gender, increased LCAT levels were associated with increased risk of CAD in women ${ }^{37)}$. 
Table 2. LCAT and atherosclerosis in humans

\begin{tabular}{lcccc}
\hline & $\begin{array}{c}\text { LCAT } \\
\text { mass/activity }\end{array}$ & CAD & IMT & Source \\
\hline General population & $=$ & YES & Holleboom AG, 2010 \\
& $\downarrow$ & NO & Haase CL, 2012 \\
\hline Subjects at high & $\downarrow$ & YES & & Hovig T, 1973; Solajic-Bozicevic N, 1994; Sethi AA, 2010; Dullaart RP, 2014 \\
cardiovascular risk & $\uparrow$ & YES & $\uparrow$ & Wells IC, 1986; Dullaart RP, 2008; Dullaart RP, 2010; Tani S, 2015 \\
& $\downarrow$ & NO & $=$ & Calabresi L, 2012 \\
\hline Carriers of genetic & $\downarrow$ & NO & $=\uparrow$ & Ayyobi AF, 2004 \\
LCAT deficiency & $\downarrow$ & NO & $\downarrow$ & Calabresi L, 2009 \\
& $\downarrow$ & NO & $\uparrow$ & Hovingh GK, 2005; Duivenvoorden R, 2011
\end{tabular}

The effect of LCAT variations on lipid and lipoprotein levels and the relation between genotypes associated with low HDL-C levels and risk of ischemic cardiovascular diseases were investigated in the following two large prospective studies: The Copenhagen City Heart Study, which started in 1976 and enrolled more than 10,000 participants, and The Copenhagen General Population Study, which started in 2003 and is currently ongoing with more than 50,000 subjects enrolled $^{38)}$. Among four common variants in LCAT regulatory and coding regions, only one (S208T) was associated with reduction in HDL-C and apoA-I levels in both studies, without any other association with biochemical markers of inflammation, glucose metabolism, and kidney disease. Furthermore, the reduction in HDL-C because of S208T variation is not associated with increased risk of myocardial infarction, ischemic heart disease, and ischemic cerebrovascular disease $^{38)}$.

\section{Subjects at High Cardiovascular Risk}

As early in 1973, the association between LCAT levels and atherosclerosis was investigated in 90 subjects with CAD in whom a decreased LCAT activity was found ${ }^{39)}$. Few years later, LCAT activity was found to be positively associated with the severity of coronary atherosclerosis in patients with coronary atherosclerosis ${ }^{40)}$. A similar study conducted in 1994 showed contradictory results. In 90 patients with coronary atherosclerosis, LCAT activity was significantly decreased compared with healthy subjects ${ }^{41)}$. Following these first studies on a limited number of subjects at high cardiovascular risk, prospective studies were performed exploring LCAT concentration/activity in high-risk patients in the last years.

Increased levels of LCAT activity were found in 74 subjects with metabolic syndrome in whom an increased carotid intima-media thickness (IMT) was also observed ${ }^{42}$. Independent of the metabolic syndrome, LCAT activity was positively associated with carotid IMT in control subjects, suggesting plasma LCAT activity as marker of subclinical atherosclerosis $^{42)}$. In line with this observation, in the PREVEND study, it was shown that higher LCAT activity correlated with increased incidence of CAD in men ${ }^{43)}$. In the IMPROVE cohort, an observational study involving 540 individuals asymptomatic for cardiovascular disease, but showing at least three cardiovascular risk factors, it was shown that low plasma LCAT levels were not associated with higher carotid IMT ${ }^{44)}$. Gender-specific analysis showed that only in women low LCAT levels correlated with decreased carotid IMT ${ }^{44)}$, similar to previous studies in the general population ${ }^{37)}$. In a very recently published cross-sectional study, the relationship between LCAT activity and triglyceride metabolism and LDL particle size was analyzed in 550 patients with one or more cardiovascular risk factors ${ }^{45)}$. The authors observed that the elevation of LCAT activity was associated with increased formation of small LDL particles that are known to be more atherogenic than large particles, but no parameters of subclinical atherosclerosis were analyzed ${ }^{45}$.

On the other hand, in some studies, it was shown that lower LCAT activity is detected in subjects at high cardiovascular risk. In 95 patients with ischemic heart disease, lower levels of LCAT activity were observed compared with control subjects matched for age, gender, and HDL-C levels ${ }^{46)}$. In line with these results, LCAT activity was decreased in 134 patients with acute myocardial infarction, and this reduction was more marked in subjects with ST elevation myocardial infarction (STEMI) than in non-STEMI patients ${ }^{47)}$. 

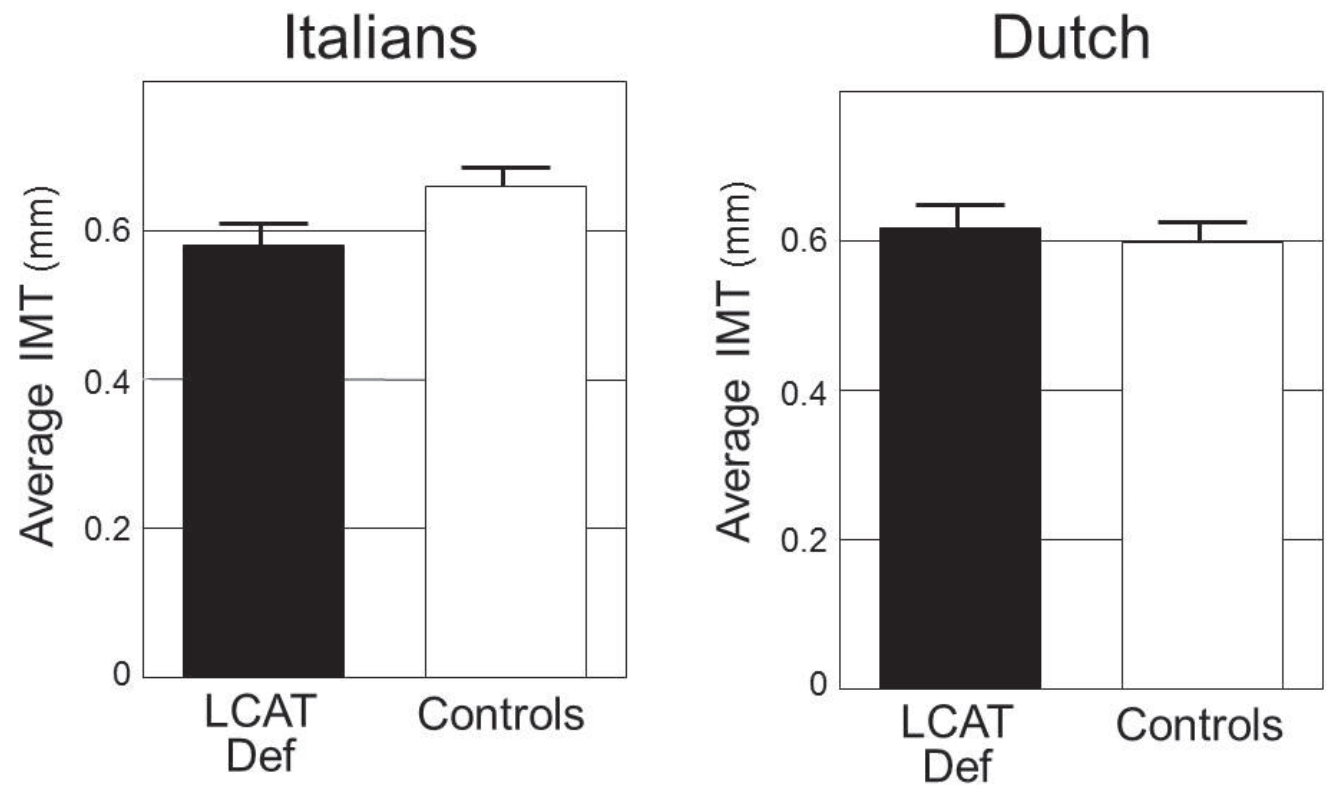

Fig. 2. Preclinical atherosclerosis in carriers of genetic LCAT deficiency. The comparison of preclinical atherosclerosis between Italian (49) and Dutch (50) studies is reported. Average IMT was measured in 12 carriers of two mutant LCAT alleles, 28 heterozygotes, and 80 control subjects in the Italian study and in 47 heterozygotes and 58 family controls in the Dutch study.

\section{Carriers of Genetic LCAT Deficiency}

Carriers of genetic LCAT deficiency represent an extreme phenotype to evaluate the correlation between the reduction of LCAT activity and atherosclerosis. Theoretically, cases with LCAT deficiency should be at increased CAD risk because of HDL deficiency and defective RCT. As in studies conducted in the general population and in high-risk subjects, results obtained in genetic LCAT deficiency are controversial.

The evidence that lack of LCAT is not associated with increased cardiovascular risk was supported by at least two independent studies. In the first study, published in 2004, two homozygotes and seven heterozygotes from a large Canadian kindred with FLD have been followed for 25 years ${ }^{48)}$. During the 25 years, no vascular events were recorded in any of the carriers aged up to 70 years ${ }^{48)}$. The homozygous carriers had only minimal increases in IMT and no plaques, whereas some IMT abnormalities were observed in four of the seven heterozygotes ${ }^{48)}$. In accordance with these data, a study conducted in 2009 in a larger number of carriers from 13 Italian families clearly showed that functional LCAT is not required for efficient atheroprotection ${ }^{49)}$. In this study, carotid IMT was measured in 12 carriers of two mutant LCAT alleles, in 28 carriers of one mutant $L C A T$ allele, and in 80 healthy age-gender-matched controls. Carriers of LCAT deficiency had a 0.07 smaller average carotid IMT and $0.21 \mathrm{~mm}$ smaller maximum carotid IMT than controls with a gene-dose dependent effect ${ }^{49)}$ (Fig. 2).

On the other hand, some studies support that genetic reduction of LCAT activity is associated with increased cardiovascular risk. In a study conducted in 2005, carotid IMT was measured in nine carriers of two mutant LCAT alleles and in 47 heterozygotes from five Dutch families with $\mathrm{FED}^{50)}$. Heterozygous carriers had $0.032 \mathrm{~mm}$ increase in average carotid IMT than family controls, but only two from 47 carriers had premature cardiovascular events ${ }^{50)}$ (Fig. 2). Lipid profile in heterozygous carriers showed a significant decrease in HDL-C, as expected, and a small but significant increase in LDL-C levels ${ }^{50}$. Carriers of two mutant LCAT alleles had greater average carotid IMT than controls, but the low number and completely different age distribution did not provide adequate power for statistical evaluation ${ }^{50)}$. Supporting the evidence that low LCAT levels are associated with increased carotid IMT, in 2011, the carotid artery wall thickening was measured by 3.0-T carotid magnetic resonance imaging (MRI) technique in two homozygous and 38 heterozygous carriers from 14 Dutch families ${ }^{51)}$. In this study, more than $80 \%$ of carriers were classified as FED, whereas less than $20 \%$ had 
mutations leading to FLD. Results clearly showed that LCAT deficient carriers had a greater increase in the thickness of carotid artery walls and 32\% increase of plaque component compared with family controls ${ }^{51)}$. In the same population, arterial stiffness that represents a strong and independent predictor of cardiovascular events was assessed by the measurement of carotid-femoral pulse wave velocity ${ }^{52}$. In accordance with the IMT data, arterial stiffness was also significantly increased in carriers of LCAT deficiency compared with controls, suggesting a higher probability of developing cardiovascular events in subjects with LCAT mutations ${ }^{52)}$.

\section{Conclusion}

LCAT was first discovered 50 years ago, but there are still fundamental questions left unanswered about LCAT biology and its role in atherosclerosis. Available data are contradictory, but clearly support the concept that reduced plasma LCAT concentrations, despite leading to reduced HDL-C levels, are not necessarily associated with increased atherosclerosis. Defective LCAT function results in the accumulation in plasma of pre $\beta$-HDL ${ }^{9}{ }^{53)}$, which act as cholesterol acceptors through $\mathrm{ABCA} 1^{54)}$, and macrophage ABCA1-dependent cholesterol efflux is enhanced in genetic LCAT deficiency ${ }^{55)}$. As cholesterol removal from macrophages is strongly and inversely associated with carotid $\mathrm{IMT}^{56}$ and more importantly with coronary heart disease (CHD) events ${ }^{57)}$, the preserved macrophage cholesterol removal associated with compromised LCAT function could well account for the lack of atherosclerosis. More investigations are warranted to clarify the role of LCAT in CHD development and to establish how LCAT could be regulated in a promising therapeutic strategy to reduce cardiovascular risk.

\section{Author Contribution}

All authors contributed to the conception, drafting, and final revision of the manuscript.

\section{Author Disclosures}

Laura Calabresi is consultant to MedImmune and received a research grant.

\section{References}

1) Glomset JA. The plasma lecithin: cholesterol acyltransferase reaction. J Lipid Res, 1968; 9: 155-162

2) Nakamura Y, Kotite L, Gan Y, Spencer TA, Fielding CJ,
Fielding PE. Molecular mechanism of reverse cholesterol transport: reaction of pre-beta-migrating high-density lipoprotein with plasma lecithin/cholesterol acyltransferase. Biochemistry, 2004; 43: 14811-14820

3) Jonas A. Lecithin cholesterol acyltransferase. Biochim Biophys Acta, 2000; 1529: 245-256

4) Warden CH, Langner CA, Gordon JI, Taylor BA, McLean JW, Lusis AJ. Tissue-specific expression, developmental regulation, and chromosomal mapping of the lecithin: cholesterol acyltransferase gene. J Biol Chem, 1989; 264: 21573-21581

5) Glukhova A, Hinkovska-Galcheva V, Kelly R, Abe A, Shayman JA, Tesmer JJ. Structure and function of lysosomal phospholipase A2 and lecithin: cholesterol acyltransferase. Nat Commun, 2015; 6: 6250

6) Piper DE, Romanow WG, Gunawardane RN, Fordstrom P, Masterman S, Pan O, Thibault ST, Zhang R, Meininger D, Schwarz M, Wang Z, King C, Zhou M, Walker NP. The high resolution crystal structure of human LCAT. J Lipid Res, 2015;

7) Albers JJ, Bergelin RO, Adolphson JL, Wahl PW. Population-based reference values for lecithin: cholesterol acyltransferase (LCAT). Atherosclerosis, 1982; 43: 369-379

8) Murakami T, Michelagnoli S, Longhi R, Gianfranceschi G, Pazzucconi F, Calabresi L, Sirtori CR, Franceschini G. Triglycerides are major determinants of cholesterol esterification/transfer and HDL remodeling in human plasma. Arterioscler Thromb Vasc Biol, 1995; 15: 1819-1828

9) Calabresi L, Pisciotta L, Costantin A, Frigerio I, Eberini I, Alessandrini P, Arca M, Bon GB, Boscutti G, Busnach G, Frasca G, Gesualdo L, Gigante M, Lupattelli G, Montali A, Pizzolitto S, Rabbone I, Rolleri M, Ruotolo G, Sampietro T, Sessa A, Vaudo G, Cantafora A, Veglia F, Calandra S, Bertolini S, Franceschini G. The molecular basis of lecithin: cholesterol acyltransferase deficiency syndromes: a comprehensive study of molecular and biochemical findings in 13 unrelated Italian families. Arterioscler Thromb Vasc Biol, 2005; 25: 1972-1978

10) Dobiasova M, Frohlich J, Sedova M, Cheung MC, Brown BG. Cholesterol esterification and atherogenic index of plasma correlate with lipoprotein size and findings on coronary angiography. J Lipid Res, 2011; 52: 566-571

11) Zhao Y, Thorngate FE, Weisgraber KH, Williams DL, Parks JS. Apolipoprotein E Is the Major Physiological Activator of Lecithin-Cholesterol Acyltransferase (LCAT) on Apolipoprotein B Lipoproteins. Biochemistry, 2005; 44: 1013-1025

12) Vitali C, Wellington CL, Calabresi L. HDL and cholesterol handling in the brain. Cardiovasc Res, 2014; 103: 405-413

13) Jonas A. Lecithin-cholesterol acyltransferase in the metabolism of high-density lipoproteins. Biochim Biophys Acta, 1991; 1084: 205-220

14) Rye KABarter PJ. Formation and metabolism of prebetamigrating, lipid-poor apolipoprotein A-I. Arterioscler Thromb Vasc Biol, 2004; 24: 421-428

15) Chetiveaux M, Lalanne F, Lambert G, Zair Y, Ouguerram K, Krempf M. Kinetics of prebeta HDL and alphaHDL in type II diabetic patients. Eur J Clin Invest, 2006; 36: 29-34 
16) Franceschini G, Maderna P, Sirtori CR. Reverse cholesterol transport: physiology and pharmacology. Atherosclerosis, 1991; 88: 99-107

17) Czarnecka HYokoyama S. Regulation of cellular cholesterol efflux by lecithin: cholesterol acyltransferase reaction through nonspecific lipid exchange. J Biol Chem, 1996; 271: 2023-2028

18) Tanigawa H, Billheimer JT, Tohyama JI, Fuki IV, Ng DS, Rothblat GH, Rader DJ. Lecithin: cholesterol acyltransferase expression has minimal effects on macrophage reverse cholesterol transport in vivo. Circulation, 2009; 120: 160-169

19) Schwartz CC, Vlahcevic ZR, Berman M, Meadows JG, Nisman RM, Swell L. Central role of high density lipoprotein in plasma free cholesterol metabolism. J Clin Invest, 1982; 70: 105-116

20) Schwartz CC, VandenBroek JM, Cooper PS. Lipoprotein cholesteryl ester production, transfer, and output in vivo in humans. J Lipid Res, 2004; 45: 1594-1607

21) Calabresi L, Simonelli S, Gomaraschi M, Franceschini G. Genetic lecithin: cholesterol acyltransferase deficiency and cardiovascular disease. Atherosclerosis, 2012; 222: 299306

22) Santamarina-Fojo S, Hoeg JM, Assmann G, Brewer HBRJr. Lecithin cholesterol acyltransferase deficiency and fish eye disease, In C. R. Scriver, A. L. Beaudet, W. S. Sly, and D. Valle (eds.), The Metabolic and Molecular Bases of Inherited Diseases. McGraw-Hill, New York, 2001; 2817-2833

23) Asztalos BF, Schaefer EJ, Horvath KV, Yamashita S, Miller M, Franceschini G, Calabresi L. Role of LCAT in HDL remodeling: investigation of LCAT deficiency states. J Lipid Res, 2007; 48: 592-599

24) Forte TM, Norum KR, Glomset JA, Nichols AV. Plasma lipoproteins in familial lecithin: cholesterol acyltransferase deficiency. Structure of low and high density lipoproteins as revealed by electron microscopy. J Clin Invest, 1971; 50: 1141-1148

25) Vaisman BL, Klein HG, Rouis M, Berard AM, Kindt MR, Talley GD, Meyn SM, Hoyt RF, Jr., Marcovina SM, Albers JJ. Overexpression of human lecithin cholesterol acyltransferase leads to hyperalphalipoproteinemia in transgenic mice. J Biol Chem, 1995; 270: 12269-12275

26) Mehlum A, Muri M, Hagve TA, Solberg LA, Prydz H. Mice overexpressing human lecithin: cholesterol acyltransferase are not protected against diet-induced atherosclerosis. APMIS, 1997; 105: 861-868

27) Berard AM, Foger B, Remaley A, Shamburek R, Vaisman BL, Talley G, Paigen B, Hoyt RF, Jr., Marcovina S, Brewer HBJr, Santamarina-Fojo S. High plasma HDL concentrations associated with enhanced atherosclerosis in transgenic mice overexpressing lecithin-cholesteryl acyltransferase. Nat Med, 1997; 3: 744-749

28) Thacker SG, Rousset X, Esmail S, Zarzour A, Jin X, Collins HL, Sampson M, Stonik J, Demosky S, Malide DA, Freeman L, Vaisman BL, Kruth HS, Adelman SJ, Remaley AT. Increased plasma cholesterol esterification by LCAT reduces diet-induced atherosclerosis in SR-BI knockout mice. J Lipid Res, 2015; 56: 1282-1295

29) Foger B, Chase M, Amar MJ, Vaisman BL, Shamburek
RD, Paigen B, Fruchart-Najib J, Paiz JA, Koch CA, Hoyt RF, Brewer HBJr, Santamarina-Fojo S. Cholesteryl ester transfer protein corrects dysfunctional high density lipoproteins and reduces aortic atherosclerosis in lecithin cholesterol acyltransferase transgenic mice. J Biol Chem, 1999; 274: 36912-36920

30) Sakai N, Vaisman BL, Koch CA, Hoyt RF, Jr., Meyn SM, Talley GD, Paiz JA, Brewer HBJr, Santamarina-Fojo S. Targeted disruption of the mouse lecithin: cholesterol acyltransferase (LCAT) gene. Generation of a new animal model for human LCAT deficiency. J Biol Chem, 1997; 272: 7506-7510

31) Ng DS, Francone OL, Forte TM, Zhang J, Haghpassand M, Rubin EM. Disruption of the murine lecithin: cholesterol acyltransferase gene causes impairment of adrenal lipid delivery and up-regulation of scavenger receptor class B type I. J Biol Chem, 1997; 272: 15777-15781

32) Furbee JW, Jr., Sawyer JK, Parks JS. Lecithin: cholesterol acyltransferase deficiency increases atherosclerosis in the low density lipoprotein receptor and apolipoprotein $\mathrm{E}$ knockout mice. J Biol Chem, 2002; 277: 3511-3519

33) Lambert G, Sakai N, Vaisman BL, Neufeld EB, Marteyn B, Chan CC, Paigen B, Lupia E, Thomas A, Striker LJ, Blanchette-Mackie J, Csako G, Brady JN, Costello R, Striker GE, Remaley AT, Brewer HBJr, Santamarina-Fojo S. Analysis of glomerulosclerosis and atherosclerosis in lecithin: cholesterol acyltransferase-deficient mice. J Biol Chem, 2001; 276: 15090-15098

34) Hoeg JM, Vaisman BL, Demosky SJ, Jr., Meyn SM, Talley GD, Hoyt RF, Jr., Feldman S, Berard AM, Sakai N, Wood D, Brousseau ME, Marcovina SM, Brewer HBJr, Santamarina-Fojo S, Marcovina S. Lecithin: cholesterol acyltransferase overexpression generates hyperalpha-lipoproteinemia and a nonatherogenic lipoprotein pattern in transgenic rabbits. J Biol Chem, 1996; 271: 4396-4402

35) Hoeg JM, Santamarina-Fojo S, Berard AM, Cornhill JF, Herderick EE, Feldman SH, Haudenschild CC, Vaisman BL, Hoyt RF, Jr., Demosky SJ, Jr., Kauffman RD, Hazel CM, Marcovina SM, Brewer HBJr. Overexpression of lecithin: cholesterol acyltransferase in transgenic rabbits prevents diet-induced atherosclerosis. Proc Natl Acad Sci U S A, 1996; 93: 11448-11453

36) Amar MJ, Shamburek RD, Vaisman B, Knapper CL, Foger B, Hoyt RF, Jr., Santamarina-Fojo S, Brewer HB, Jr., Remaley AT. Adenoviral expression of human lecithincholesterol acyltransferase in nonhuman primates leads to an antiatherogenic lipoprotein phenotype by increasing high-density lipoprotein and lowering low-density lipoprotein. Metabolism, 2009; 58: 568-575

37) Holleboom AG, Kuivenhoven JA, Vergeer M, Hovingh GK, van Miert JN, Wareham NJ, Kastelein JJ, Khaw KT, Boekholdt SM. Plasma levels of lecithin: cholesterol acyltransferase and risk of future coronary artery disease in apparently healthy men and women: a prospective casecontrol analysis nested in the EPIC-Norfolk population study. J Lipid Res, 2010; 51: 416-421

38) Haase CL, Tybjaerg-Hansen A, Ali QA, Schou J, Nordestgaard BG, Frikke-Schmidt R. LCAT, HDL Cholesterol and Ischemic Cardiovascular Disease: A Mendelian Randomization Study of HDL Cholesterol in 54,500 Individ- 
uals. J Clin Endocrinol Metab, 2012; 97: E248-E256

39) Hovig T, Gjone E. Familial plasma lecithin: cholesterol acyltransferase (LCAT) deficiency. Ultrastructural aspects of a new syndrome with particular reference to lesions in the kidneys and the spleen. Acta Pathol Microbiol Scand A, 1973; 81: 681-697

40) Wells IC, Peitzmeier G, Vincent JK. Lecithin: cholesterol acyltransferase and lysolecithin in coronary atherosclerosis. Exp Mol Pathol, 1986; 45: 303-310

41) Solajic-Bozicevic N, Stavljenic-Rukavina A, Sesto M. Lecithin-cholesterol acryltransferase activity in patients with coronary artery disease examined by coronary angiography. Clin Investig, 1994; 72: 951-956

42) Dullaart RP, Perton F, Sluiter WJ, De VR, Van TA. Plasma lecithin: cholesterol acyltransferase activity is elevated in metabolic syndrome and is an independent marker of increased carotid artery intima media thickness. J Clin Endocrinol Metab, 2008; 93: 4860-4866

43) Dullaart RP, Perton F, van der Klauw MM, Hillege HL, Sluiter WJ. High plasma lecithin: cholesterol acyltransferase activity does not predict low incidence of cardiovascular events: possible attenuation of cardioprotection associated with high HDL cholesterol. Atherosclerosis, 2010; 208: 537-542

44) Calabresi L, Baldassarre D, Simonelli S, Gomaraschi M, Amato M, Castelnuovo S, Frigerio B, Ravasi A, Sansaro D, Kauhanen J, Rauramaa R, de FU, Hamsten A, Smit AJ, Mannarino E, Humphries SE, Giral P, Veglia F, Sirtori CR, Franceschini G, Tremoli E. Plasma lecithin: cholesterol acyltransferase and carotid intima-media thickness in European individuals at high cardiovascular risk. J Lipid Res, 2011; 52: 1569-1574

45) Tani S, Takahashi A, Nagao K, Hirayama A. Association of lecithin-cholesterol acyltransferase activity measured as a serum cholesterol esterification rate and low-density lipoprotein heterogeneity with cardiovascular risk: a crosssectional study. Heart Vessels, 2015;

46) Sethi AA, Sampson M, Warnick R, Muniz N, Vaisman B, Nordestgaard BG, Tybjaerg-Hansen A, Remaley AT. High pre-beta1 HDL concentrations and low lecithin: cholesterol acyltransferase activities are strong positive risk markers for ischemic heart disease and independent of HDL-cholesterol. Clin Chem, 2010; 56: 1128-1137

47) Dullaart RP, Tietge UJ, Kwakernaak AJ, Dikkeschei BD, Perton F, Tio RA. Alterations in plasma lecithin: cholesterol acyltransferase and myeloperoxidase in acute myocardial infarction: Implications for cardiac outcome. Atherosclerosis, 2014; 234: 185-192

48) Ayyobi AF, McGladdery SH, Chan S, John Mancini GB, Hill JS, Frohlich JJ. Lecithin: cholesterol acyltransferase (LCAT) deficiency and risk of vascular disease: 25 year follow-up. Atherosclerosis, 2004; 177: 361-366

49) Calabresi L, Baldassarre D, Castelnuovo S, Conca P, Boc- chi L, Candini C, Frigerio B, Amato M, Sirtori CR, Alessandrini P, Arca M, Boscutti G, Cattin L, Gesualdo L, Sampietro T, Vaudo G, Veglia F, Calandra S, Franceschini G. Functional lecithin: cholesterol acyltransferase is not required for efficient atheroprotection in humans. Circulation, 2009; 120: 628-635

50) Hovingh GK, Hutten BA, Holleboom AG, Petersen W, Rol P, Stalenhoef A, Zwinderman AH, de GE, Kastelein JJ, Kuivenhoven JA. Compromised LCAT function is associated with increased atherosclerosis. Circulation, 2005; 112: 879-884

51) Duivenvoorden R, Holleboom AG, van den BB, Nederveen AJ, de GE, Hutten BA, Schimmel AW, Hovingh GK, Kastelein JJ, Kuivenhoven JA, Stroes ES. Carriers of lecithin: cholesterol acyltransferase gene mutations have accelerated atherogenesis as assessed by carotid 3.0-T magnetic resonance imaging. J Am Coll Cardiol, 2011; 58: $2481-2487$

52) van den Bogaard B, Holleboom AG, Duivenvoorden R, Hutten BA, Kastelein JJ, Hovingh GK, Kuivenhoven JA, Stroes ES, van den Born BJ. Patients with low HDL-cholesterol caused by mutations in LCAT have increased arterial stiffness. Atherosclerosis, 2012; 225: 481-485

53) Calabresi L, Simonelli S, Conca P, Busnach G, Cabibbe M, Gesualdo L, Gigante M, Penco S, Veglia F, Franceschini G. Acquired lecithin: cholesterol acyltransferase deficiency as a major factor in lowering plasma HDL levels in chronic kidney disease. J Intern Med, 2015; 277: $552-561$

54) Favari E, Lee M, Calabresi L, Franceschini G, Zimetti F, Bernini F, Kovanen PT. Depletion of pre-beta-high density lipoprotein by human chymase impairs ATP-binding Cassette Transporter A1- but not Scavenger Receptor Class B Type I-mediated lipid efflux to high density lipoprotein. J Biol Chem, 2004; 279: 9930-9936

55) Calabresi L, Favari E, Moleri E, Adorni MP, Pedrelli M, Costa S, Jessup W, Gelissen IC, Kovanen PT, Bernini F, Franceschini G. Functional LCAT is not required for macrophage cholesterol efflux to human serum. Atherosclerosis, 2009; 204: 141-146

56) Khera AV, Cuchel M, De LL-M, Rodrigues A, Burke MF, Jafri K, French BC, Phillips JA, Mucksavage ML, Wilensky RL, Mohler ER, Rothblat GH, Rader DJ. Cholesterol efflux capacity, high-density lipoprotein function, and atherosclerosis. N Engl J Med, 2011; 364: 127-135

57) Saleheen D, Scott R, Javad S, Zhao W, Rodrigues A, Picataggi A, Lukmanova D, Mucksavage ML, Luben R, Billheimer J, Kastelein JJ, Boekholdt SM, Khaw KT, Wareham N, Rader DJ. Association of HDL cholesterol efflux capacity with incident coronary heart disease events: a prospective case-control study. Lancet Diabetes Endocrinol, 2015; 3: 507-513 